\title{
Dynamic Splinting for Hallux Valgus and Hallux Varus: A Pilot Study
}

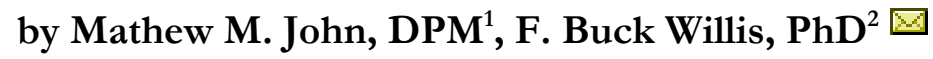

The Foot and Ankle Online Journal 3 (1): 1

Background: Hallux Abductovalgus (HAV) is a deformity causing excessive angulation of the great toe towards the second toe, and this condition affects over 3.6 million Americans. Conversely hallux varus is excessive medial deviation and this pathology occurs secondary to procedures correcting hallux valgus and as a pediatric/congenital anomaly. The purpose of this pilot study was to report the benefits that Dynamic Splinting (DS) had on reducing contracture in hallux varus and hallux valgus.

Methods: Ten patients treated with DS were examined and these patients included six diagnosed with HAV and four patients diagnosed with hallux varus. The outcome measures reported include changes in maximal, active range of motion (AROM) and resting alignment.

Results: The patients treated for HAV regained a mean $10^{\circ}$ active range of motion (AROM) in one month. The patients treated for hallux varus regained a mean $9^{\circ}$ AROM in 3 months.

Conclusions: Dynamic splinting was beneficial for all patients in this study. The HAV patients regained a mean $10^{\circ}$ of AROM (mean duration 1 month) and the hallux varus patients gained a mean $9^{\circ}$ (mean duration 2 months). The modality which delivered low-torque stretching for prolonged durations was effective in reducing these conditions without requiring surgery.

Key words: Contracture reduction, Dynasplint, home therapy, rehabilitation.

Accepted: December, 2009

Published: January, 2010

This is an Open Access article distributed under the terms of the Creative Commons Attribution License. It permits unrestricted use, distribution, and reproduction in any medium, provided the original work is properly cited. (The Foot and Ankle Online Journal (www.faoj.org)

$\mathrm{H}$ allux Abductovalgus (HAV) is a bunion deformity causing abnormal angulation of the great toe towards the second toe. The incidence rate of $\mathrm{HAV}$ is $1 \%$ of all Americans ${ }^{1-4}$ and this includes $9 \%$ of women over the age of 60 years old. This pathology causes pain, inflammation, and reduced or impaired functioning of the hallux in ambulation.

Address correspondence to: University of Phoenix: Axia College, Adjunct Professor Health Sciences and Dynasplint Systems, Clinical Research Director.

Email: BuckPhD@yahoo.com

${ }^{1}$ Ankle \& Foot Centers 2790 Sandy Point Rd. \#300 Marietta GA, 30066. (770) 977-3668.

${ }^{2}$ University of Phoenix: Axia College, Adjunct Professor Health Sciences, Dynasplint Systems, Clinical Research Director , PO Box 1735 San Marcos TX 78667 (512) 297-1833
The current standard of care in treating this condition includes nonsurgical treatment such as shoe modification followed by surgical management. ${ }^{5-8}$ Complications of surgical treatment are not without risk though. Osteotomies of the first metatarsal such as the Lapidus and distal chevron procedure have caused significant incidence of hallux varus.

Hallux varus refers to excessive medial deviation of the great toe. In addition to the frequent iatrogenic postoperative variety, hallux varus occurs as a pediatric/congenital pathology and as a rheumatic or posttraumatic condition. ${ }^{9,10}$ This connective tissue pathology is also currently only treated with surgical procedures. $^{3-6,11}$ 


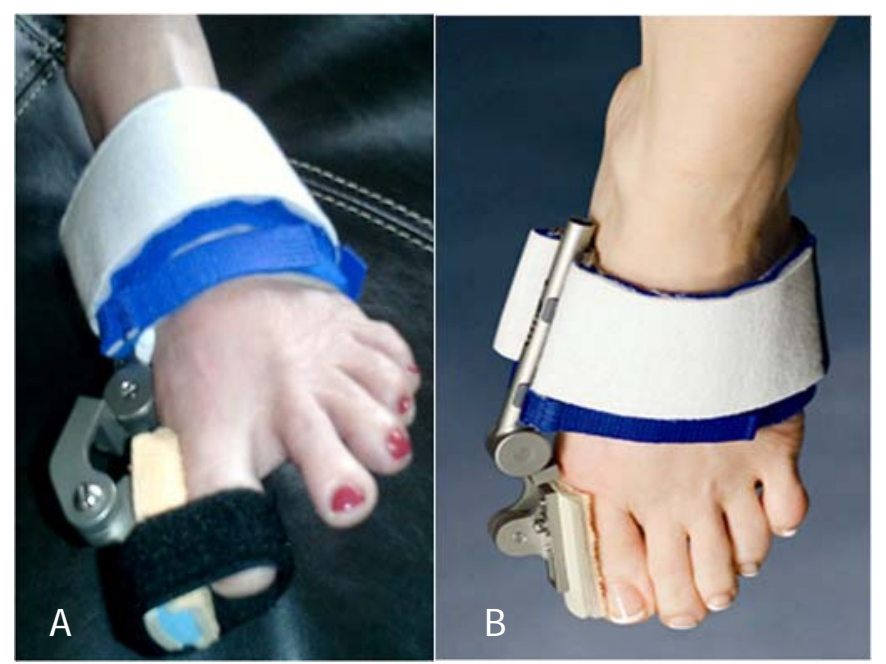

Figure 1A and 1B Hallux valgus (A) and hallux varus (B) Dynasplint.

Similar pathologies have symptomatic contracture which is defined as the molecular shortening of the connective tissue and these pathologies occur from postoperative or posttraumatic arthrofibrosis ${ }^{12-14}$, immobilization ${ }^{15,16}$, or occur secondarily to excessive neuromuscular tone. ${ }^{16,17}$ A study by Usuba, et. al., examined nonsurgical, therapeutic treatments for contracture that was caused by surgical immobilization in rats. ${ }^{15}$ After 40 days of surgical immobilization the mean rat knee flexion contracture was $-125^{\circ}(n=60)$. Usuba, et. al., then tested the interaction of four protocols: Stretching with high vs. low torque and stretching of prolonged duration vs. short duration. The only statistically significant difference seen between treatment protocols was found with combined protocols of low-torque stretching for prolonged durations.

This combination of low-torque stretching for prolonged durations is exactly what was used in the Dynasplint systems. A study by John, et. al., examined efficacy of the Dynasplint modality for reduction of contracture causing Hallux Limitus (HL). ${ }^{14}$ In this study, 50 patients were enrolled after diagnosis of HL which occurred following a bunionectomy or cheilectomy.

The duration of this randomized study was eight weeks, and experimental patients received low-torque, prolonged stretching in the metatarsal joint Dynasplint (MTD) for 60 minutes, three times per day.

The dependent variable in Dr. John's study was change in Active Range of Motion (AROM) and there was a significant change for the experimental patients following use of this home therapy modality $(\mathrm{P}<$ $0.001, \mathrm{~T}=4.224)$. Experimental patients in this study regained a mean $32^{\circ}$ change in AROM, extension compared to only a mean $10^{\circ}$ change in AROM for control patients. Dr John's randomized, controlled trial showed conclusive efficacy of the MTD modality. ${ }^{14}$ A retrospective study $(\mathrm{N}=61)$ by Kalish and Willis showed comparable results in patients' regaining $73 \%$ dorsiflexion at the metatarsal joint after 4 weeks. ${ }^{13}$ The purpose of this pilot study was to report the benefits that Dynamic Splinting (DS) had on reducing contracture in hallux varus and hallux valgus.

\section{Methods}

Ten patients' were treated with Dynamic Splinting (DS) in this report, (six with HAV and four with hallux varus). The modality can be seen in Figure $1 \mathrm{AB}$ and this unit delivers force and counter force to achieve elongation of connective tissue for contracture reduction. The same unit may be used for both lateral and medial stretching and this alteration is analogous to the Metatarsal Dynasplint that stretches both in plantarflexion ${ }^{12}$ and dorsiflexion. ${ }^{13,14}$ 
The initial fitting for patients included customization of the unit (patient's foot length, girth, and varying degrees of hallux edema), and training on donning and doffing of the devices. Patients also received instruction on safety, general wear and care, and standardized tension setting goals. Dynamic splinting employs the protocol of low-load stretching for contracture reduction through an appropriate biomechanical device which increases the joint's time at end range (of motion). ${ }^{12-14,16,17}$

Each patient was instructed to wear the DS initially for 10 minutes, three times a day (tid) while seated, with an initial tension setting of \#1 (0.10 foot pound of torque). Patients were instructed to sequentially increase the wearing time until they were comfortable wearing the unit for 60 minutes, tid. This lowest intensity was used for becoming accustomed to the system, and the patients were instructed to increase tension on increment every two weeks after they were comfortable wearing the unit for 60 minutes, tid.

\section{Results}

The outcome measurements in this study included changes in maximal AROM for all patients and changes in hallux alignment measured in resting, weight bearing position. The patients treated for HAV regained a mean $10^{\circ}$ AROM (one month) and the patients treated for hallux varus regained a mean $9^{\circ}$ AROM in 3 months. Measurement of hallux alignment was taken while resting (weight bearing). This variable yielded comparable gains of Hallux abduction $10^{\circ}$ (HAV) and $9^{\circ}$ for adduction (hallux varus).

\section{Conclusion}

The purpose of this study was to report the benefits that dynamic splinting had on reducing contracture in hallux varus and hallux valgus. This examination of the new modality for contracture reduction was beneficial in restoring AROM and achieving a more optimal hallux alignment. The DS employed a proven protocol in using low-torque, prolonged stretching to reduce contracture without surgery. ${ }^{13-17}$ While surgical resolution of hallux varus and HAV are the current standard of care, therapeutic endeavors have been prescribed effectively for treatment of post operative rehabilitation $^{18}$, and the DS used in this study answered the call for therapeutic treatment for hallux contracture pathologies. , $^{3,12-14,18}$

The use of dynamic splinting in this pilot study caused no adverse events, and a future randomized, controlled trial would determine if this new modality is effective in separate populations of patients with hallux abducto valgus and hallux varus.

\section{References}

1. Shima H, Okuda R, Yasuda T, Jotoku T, Kitano N, Kinoshita $\mathrm{M}$ : Radiographic measurements in patients with hallux valgus before and after proximal crescentic osteotomy. J Bone Joint Surg 91A (6): 1369 - 1376, 2009.

2. Selner AJ, Selner MD, Cyr RP, Noiwangmuang W:

Revisional Am Podiatr Med Assoc 4(4): 341 - 346, 2004.

3. Miller JW: Acquired hallux varus: a preventable and correctable disorder. J Bone Joint Surg 57A (2):183 - 188, 1975.

4. Lui TH: Technique tip: minimally invasive approach of tendon transfer for correction of hallux varus. Foot Ankle Int 30(10): 1018 - 1021, 2009.

5. Miller RJ, Rattan N, Sorto L: The geriatric bunion: correction of metatarsus primus varus and hallux valgus with the Swanson total joint implant. J Foot Surg 22 (3):263 - 270, 1983.

6. Vanore JV, Christensen JC, Kravitz SR, Schuberth JM, Thomas JL, Weil LS, Zlotoff HJ, Mendicino RW, Couture SD; [Clinical Practice Guideline First Metatarsophalangeal Joint Disorders Panel of the American College of Foot and Ankle Surgeons]: Diagnosis and treatment of first metatarsophalangeal joint disorders. Section 3: Hallux varus. J Foot Ankle Surg 42 (3): $137-142,2003$.

7. Orzechowski W, Dragan S, Romaszkiewicz P, Krawczyk A, Kulej M, Morasiewicz L: Evaluation of follow-up results of McBride operative treatment for hallux valgus deformity. Ortop Traumatol Rehabil 10(3): 261 - 273, 2008.

8. Jahss MH: Disorders of the hallux and first ray. Disorders of the Foot and Ankle: Medical and Surgical Management. $2^{\text {nd }}$

ed. Philadelphia, Pa: WB Saunders Co, 1084 - 1089, 1991.

9. Trnka HJ, Hofstaetter SG, Easley ME: Intermediate-term results of the Ludloff osteotomy in one hundred and eleven feet. Surgical technique. J Bone Joint Surg 91A (Suppl 2 Pt 1): 156 168, 2009.

10. Oloff LM, Bocko AP: Application of distal metaphyseal osteotomy for treatment of high intermetatarsal angle bunion deformities. J Foot Ankle Surg 37(6): 481 - 489, 1998.

(C) The Foot and Ankle Online Journal, 2010 
11. Bilotti MA, Caprioli R, Testa J, Cournoyer R Jr, Esposito FJ: Reverse Austin osteotomy for correction of hallux varus. J Foot Surg 26 (1): 51 - 55, 1987.

12. John MM, Willis FB, Portillo A: Dynamic splinting for runner's toe: a case report with gait analysis. J Am Podiatric Med Assoc 99(4): 367 - 370, 2009.

13. Kalish SA, Willis FB: Hallux limitus and dynamic splinting: a retrospective series. The Foot \& Ankle Online Journal 2 (4): 1, 2009.

14. John MM, Kalish SR, Perns SV, Willis, FB. Dynamic Splinting for Hallux Limitus: a Randomized, Controlled Trial. Journal American Podiatric Medical Assoc (In-Press)

15. Usuba M, Akai M, Shirasaki Y, Miyakawa S: Experimental joint contracture correction with low torque -long duration repeated stretching. Clin Orthop Relat Res 456: 70 - 88, 2007.

16. Willis FB: Post-TBI Gait rehabilitation. Applied Neurol 3(7): $25-26,2007$.

17. Lai J, Jones M, Willis B: Effect of dynamic splinting on excessive plantar flexion tone/contracture: A controlled, crossover study. Proceedings of the $16^{\text {th }}$ European Congress of Physical and Rehabilitation Medicine. Minerva Medica pubs, Italy, 106 - 109, August, 2008.

18. Schuh R, Hofstaetter SG, Adams SB Jr, Pichler F, Kristen $\mathrm{KH}$, Trnka HJ: Rehabilitation after hallux valgus surgery: importance of physical therapy to restore weight bearing of the first ray during the stance phase. Phys Ther 89(9): 934 - 945, 2009. 